\title{
Optimal Reactive Power for Voltage Stability in Distribution Systems Connected Wind Turbine Farm using Particle Swarm Optimization
}

\author{
Mongkol Treekijjanon, ${ }^{\mathrm{a},{ }^{*}}$, Suparat Srimongkol ${ }^{\mathrm{c}}$, Uthen Leeton ${ }^{\mathrm{b}}$, Boonruang Marungsri ${ }^{\mathrm{b}, *}$, and Thanatchai \\ Kulworawanichpong ${ }^{\mathrm{b}}$ \\ ${ }^{a}$ Graduate student in Energy management, Engineering, Institute of Engineering, Suranaree University of Technology, \\ Nakhon Ratchasima, 30000, Thailand \\ ${ }^{\mathrm{b}}$ School of Electrical Engineering, Institute of Engineering, Suranaree University of Technology, \\ Nakhon Ratchasima, 30000, Thailand \\ ${ }^{\mathrm{c}}$ Engineering and Planning Section, Division of Engineering and Services, Provincial Electricity Authority Area 3
}

(Northeast) Nakhonratchasima, 30000, Thailand

*Corresponding Author Email:bmshvee@ sut.ac.th, mongkol.to@gmail.com

\begin{abstract}
This paper illustrates optimal reactive power setting for voltage stability in power distribution system affected by wind turbine farm high terminal voltage using particle swarm optimization to inquire optimal solution. It involves the implementation of disturbance analyzing device to compare the result of setting reactive compensator. In this research, to optimize the overall voltage limitation, three decision variables were considered, which are i)active/reactive power generated from wind turbine farm plants, ii) specified voltage magnitude and all node limitation and iii) power factor control. Particle swarm optimization (PSO) is well-known and widely accepted as a potential intelligent search method for solving optimization problems .'WA-YU" wind turbine farm project rated 8.0 MW, 22kV of Provincial Electricity Authority (PEA) in Nakhon Ratchasima, Thailand at feeder ten was employed as a case study. Results showed that PSO can search optimal reactive power to solve power flow problems efficiently related the best power factor. The voltage limitation was controlled in $\pm 5 \%$ range of nominal voltage $(22 \mathrm{kV})$ based on PEA's regulation grid terms connected with a network of 2008. The controlled voltage provided a benefit which did not affect other power users connected in the same feeder circuit.
\end{abstract}

Keywords: optimal reactive power flow, particle swarm optimization, wind turbine farm, overvoltage limitation.

\section{Introduction}

The issue of global warming and the soaring cost of fuel, energy-efficient and environment-friendly heating and cooling applications ranging from domestic and commercial to industrial sectors is a promising development ${ }^{(1)}$. The renewable energy is cooperated and installed in distribution power systems to contain two or more power generation sources in order to balance each other's strengths and weaknesses ${ }^{(2)}$. There are many types of renewable energy sources such as the wind, solar, biomass, etc. These sources are environmentally friendly and the use of primary energy carriers has been installed increasingly all over the world. The sources mentioned above can be divided into two groups: controlled sources and uncontrolled sources. Controlled sources mean that the output power can be easily controlled to the goal power; for example, biogas or biomass power plant. It is obvious that output power from uncontrolled sources is unpredictable and independent of human action. Solar and wind power plants are environmentally uncontrolled sources ${ }^{(3)}$. The wind turbine technology is now strongly presented in the electricity market and it can be seen as a vision of the future. When the wind power plant is installed to serve loads in LV/MV power distribution grids, energy flow in the distribution network must be well managed in order to 
minimize total power losses or maximize net energy transaction in the network and voltage stability.

Thailand's government has a policy directly on the electricity market for generated power from renewable energy as an alternative energy development plan (AEDP) 2015. The goal of renewable energy source is $25 \%$ of the total demand within $2021^{(12)}$. Wind turbine generation is implemented to serve power demand. Wind turbine power is limited in terms of suitable areas for the installation and also to consider the issue of power quality and the impact on electric power system to other users in the same system such as over voltage problem.

This paper organizes a total of six sections. Next section, Section two, electric power distribution grid with wind turbine power plant describes overall power distribution grid and wind power model. Section three is optimal problems structure corresponding mathematical expressions of its objective and various practical constraints. Section four is definition a solution method of PSO. Section five gives simulation results and discussion. The conclusion is in Section six.

\section{Electric Power Distribution Grid with Wind Turbine Farm}

Various renewable energy generations have been developed to reduce greenhouse gas emissions and increasingly attractive in solving global problems such as the environmental pollution and energy shortage. The renewable energy generation, which is susceptible to changes in the weather and environmental conditions, is expected to be increasingly connected to distribution systems in the future ${ }^{(4)}$. However, the disadvantage is that wind power generation is intermittent, depending upon weather conditions. Short-term energy storage is necessary in order to get a smooth power output from a wind turbine ${ }^{(5)}$.

Electric power distribution is the final stage in the delivery of electricity to end users. A distribution system's network carries electricity from high-voltage power transmission systems and therefore delivers it to consumers via low-voltage residential power cables. The electric power distribution grid with renewable energy is defined as an integration of electrical loads and generation as shown in Fig. $1^{(6-7)}$.

A turbine with rotor axis of rotation that is horizontal to the ground is called a HAWT (Horizontal Axis Wind Turbine). HAWTs are representative of the majority of all large-scale wind turbines today. These turbines are operated in an upwind manner, where the rotor plane is actively positioned to be directly upwind of the tower through the use of a yaw motor that rotates the entire nacelle. Wind passing over the turbine blades produces lift and this then induces a rotational torque. This test system of the wind farm is doubly fed induction generator (DFIG) which its layout and component of Gamesa type G114-2.0 MW are shown in Fig. $2^{(8)}$.

Wind turbine control is typically divided into four primary regions, as seen in Fig. 3. Region 1 spans operation from startup to the 'cut-in' wind speed where the generator is turned on and starts producing power.

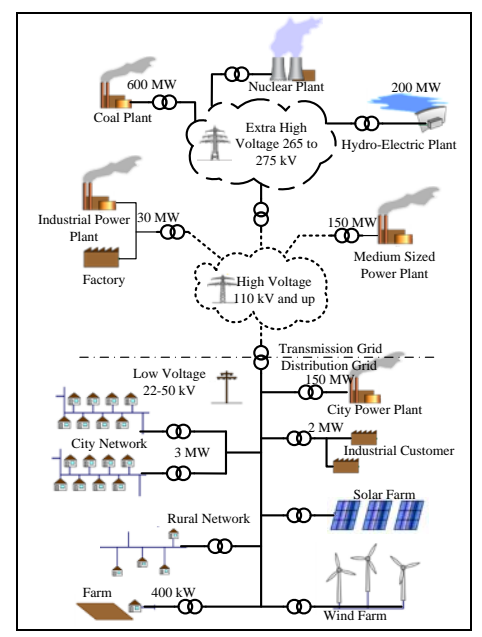

Fig. 1. Renewable energy plant for power distribution $\operatorname{grid}^{(9)}$.

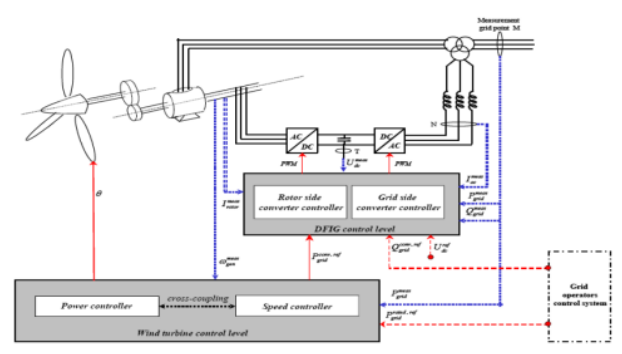

Fig 2. Layout and component of Gamesa type G114-2.0 MW.

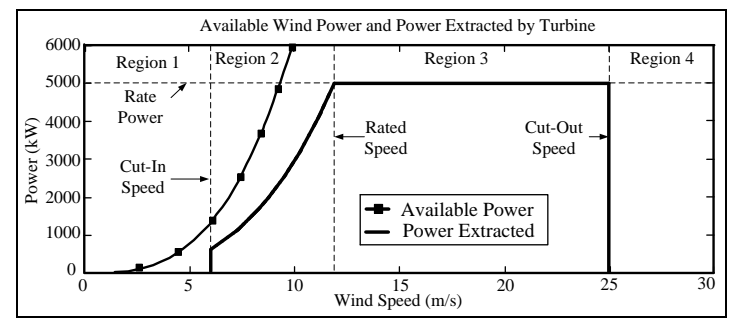

Fig. 3. Wind power, turbine power, and operating regions for an example $5 \mathrm{MW}$ turbine. 
When wind speeds are above cut-in, but still too low to produce maximum power, the turbine is said to be in Region 2. In this below rated region, the objective is to maximize aerodynamic efficiency to capture as much energy as possible from the wind stream. In Region 3, wind speeds are high enough to drive the generator to its rated power output; in this case, the goal is to regulate speed and power safely at rated levels. Region 4 occurs when the turbine shuts down due to high wind speeds to prevent damage to the turbine.

\section{Optimal Problem Formulation}

The optimal problem consists of a nonlinear objective function defined with nonlinear constraints. The general optimal problem can be expressed as a constrained optimization problem as follows.

$$
\begin{array}{ll}
\text { Minimize } & f(x) \\
\text { Subject to } & g(x)=0 \text {, equality constraints } \\
& h(x) \leq 0, \text { inequality constraints }
\end{array}
$$

By converting both equality and inequality constraints into penalty terms, they can be added to form the penalty function as described in (1) and (2).

$$
\begin{aligned}
& P(x)=f(x)+\Omega(x) \\
& \Omega(x)=\rho\left\{g^{2}(x)+[\max (0, h(x))]^{2}\right\}
\end{aligned}
$$

Where $P(x)$ is the penalty function

$\Omega(x)$ is the penalty term

$\rho$ is the penalty factor

By using a concept of the penalty method, the constrained optimization problem is transformed into an unconstrained optimization problem in which the penalty function described above is minimized ${ }^{(10)}$.

\subsection{Objective Function and Constraints}

Optimal reactive power controls appropriate bus voltage. In this paper applied power flow analysis determines the appropriate value by using particle swarm optimization to analyze the reactive power compensation of wind farm. The objective function is load voltage derivation (LVD) as shown in equation (3).

$$
\operatorname{Min} f_{1}(x, u)=\sum_{k=1}^{n}\left(\frac{V_{k}^{r e f}-V_{K}}{V_{k}^{r e f}}\right)^{2}
$$

Where: $V_{\text {ref }}$ is a reference voltage or nominal voltage (1 p.u./22 kV), $V_{k}$ is voltage at bus $\mathrm{k}, \quad x$ is state of the system, $u$ variable change. For this paper, reactive power can be controlled by adjusting the real power, power factor which is shown in equation (4).

$$
Q_{i}=F^{*} P_{G i} * \tan \left(\cos ^{-1}\left(P F_{i}\right)\right)
$$

Where: $Q_{i}$ is reactive power (MVAR), $P_{G i}$ is real power from a wind turbine, $F$ is constant operate mode; $(+1)$ for $(+\mathrm{Q})$ and (-1) for(-Q) and $P F_{i}$ is power factor.

\subsection{System Constraints}

The controllable system quantities are generator MW, controlled voltage magnitude, and reactive power injection from wind turbine farm related power factor. The objective use herein is to minimize the load voltage derivation (LVD) function by optimizing the control variables within their limits. Therefore, no violation on other quantities (e.g. MVA flow of transmission lines, load bus voltage magnitude, generator MVAR) occurs in normal system operating conditions. These are system constraints to be formed as equality and inequality constraints as shown below.

Equality constraint: Power flow equations as (5) to (6)

$$
\begin{aligned}
& P_{G, i}-P_{D, i}-\sum_{j=1}^{N_{B}}\left|V_{i}\left\|V_{j}\right\| Y_{i, j}\right| \cos \left(\theta_{i, j}-\delta_{i}+\delta_{j}\right)=0 \\
& Q_{G, i}-Q_{D, i}+\sum_{j=1}^{N_{B}}\left|V_{i}\left\|V_{j}\right\| Y_{i, j}\right| \sin \left(\theta_{i, j}-\delta_{i}+\delta_{j}\right)=0
\end{aligned}
$$

Where: $\quad P_{G i}$ is the real power generation at bus $i$

$Q_{G i}$ is the reactive power generation at bus $i$

$P_{D i}$ is the real power demand at bus $i$

$Q_{D i}$ is the reactive power demand at bus $i$

$N_{B}$ is the total number of buses

$\theta_{i, j}$ is the angle of bus admittance element $i, j$

$Y_{i, j}$ is the magnitude of bus admittance element $i, j$

Inequality constraint: Variable limitations as in (7) to (10)

$$
\begin{aligned}
& V_{i}^{\min } \leq V_{i} \leq V_{i}^{\max } \\
& P F_{W T, i}^{\min } \leq P F_{W T, i} \leq P F_{W T, i}^{\max } \\
& Q_{W T, i}^{\min } \leq Q_{W T, i} \leq Q_{W T, i}^{\max } \\
& P_{W T, i}^{\min } \leq P_{W T, i} \leq P_{W T, i}^{\max }
\end{aligned}
$$


Where: $V_{i}^{\min }, V_{i}^{\max }$ are upper and lower limits of voltage magnitude at bus $i$

$P F_{W T, i}^{\min }, P F_{W T, i}^{\max }$ are upper and lower limits of the power factor of wind turbine farm module $i$ $Q_{W T, i}^{\min }, Q_{W T, i}^{\max }$ are upper and lower limits of reactive power of wind turbine farm module $i$

$P_{W T, i}^{\min }, P_{W T, i}^{\max } \quad$ are upper and lower limits of power generated by wind turbine farm module $\mathrm{i}$

The penalty function can be formulated as follows.

$$
P(x)=f_{1}(x, u)+\Omega_{V}+\Omega_{P F}+\Omega_{Q}+\Omega_{W T}
$$

Where:

$$
\begin{aligned}
& \Omega_{P}=\rho \sum_{i=1}^{N_{B}}\left\{P_{G, i}-P_{D, i} \sum_{j=1}^{N_{B}}\left|V_{i}\left\|V_{j}\right\| Y_{i j}\right| \cos \left(\theta_{i, j}-\delta_{i}+\delta_{j}\right)\right\}^{2} \\
& \Omega_{Q}=\rho \sum_{i=1}^{N_{B}}\left\{Q_{G, i}-Q_{D, i}+\sum_{j=1}^{N_{B}}\left|V_{i}\left\|V_{j}\right\| Y_{i j}\right| \sin \left(\theta_{i j}-\delta_{i}+\delta_{j}\right)\right\}^{2} \\
& \Omega_{Q, W T}=\rho \sum_{i=1}^{N_{C}}\left\{\max \left(0, Q_{W T, i}-Q_{W T, i}^{\max }\right)\right\}^{2}+\rho \sum_{i=1}^{N_{C}}\left\{\max \left(0, Q_{W T, i}^{\min }-Q_{W T, i}\right)\right\}^{2} \\
& \Omega_{P F}=\rho \sum_{i=1}^{N_{T}}\left\{\max \left(0, P F_{W T, i}-P F_{W T, i}^{\max }\right)\right\}^{2}+\rho \sum_{i=1}^{N_{T}}\left\{\max \left(0, P F_{W T, i}^{\min }-P F_{W T, i}\right)\right\}^{2} \\
& \Omega_{V}=\rho \sum_{i=1}^{N_{B}}\left\{\max \left(0, V_{i}-V_{i}^{\max }\right)\right\}^{2}+\rho \sum_{i=1}^{N_{B}}\left\{\max \left(0, V_{i}^{\min }-V_{i}\right)\right\}^{2} \\
& \Omega_{P, W T}=\rho \sum_{i=1}^{N_{G}}\left\{\max \left(0, P_{W T, i}-P_{W T, i}^{\max }\right)\right\}^{2}+\rho \sum_{i=1}^{N_{G}}\left\{\max \left(0, P_{W T, i}^{\min }-P_{W T, i}\right)\right\}^{2}
\end{aligned}
$$

$N_{G}$ is the total number of generators

$N_{C}$ is the total number of reactive power sources

$N_{T}$ is the total number of transformers

\section{Particle Swarm Optimization (PSO)}

Kennedy and Eberhart developed a particle swarm optimization algorithm based on the behavior of individuals (i.e., particles or agents) of a swarm ${ }^{(11)}$. Its roots are in zoologist's modeling of the movement of individuals (i.e., fish, birds, and insects) within a group. It has been noticed that members of the group seem to share information among them to lead to increased efficiency of the group. The particle swarms optimization algorithm searches in parallel using a group of individuals similar to other AI-based heuristic optimization techniques. Each individual corresponds to a candidate solution to the problem. Individuals in a swarm approach to the optimum through its present velocity, previous experience, and the experience of its neighbors. In a physical $n$-dimensional search space, the position and velocity of individual $i$ are represented as the velocity vectors. Using this information individual $i$ and its updated velocity can be modified under the following equations in the particle swarm optimization algorithm. The procedure of the particle swarm optimization can be summarized in the flow diagram of Fig. 4. Leeton et $\mathrm{al}^{\left({ }^{(12)}\right.}$ found that the PSO-based optimal power flow method gave the best results when compared with results obtained by the genetic algorithm and the Broyden-Fletcher-GoldfarbShanno (BFGS) algorithm.

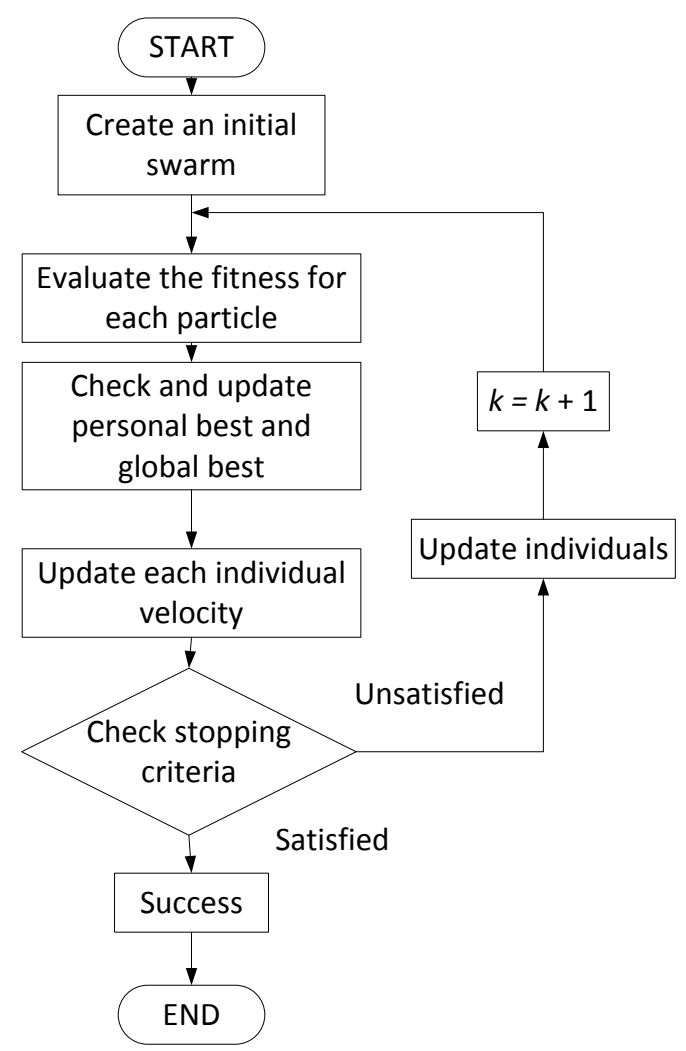

Fig. 4. Flowchart of the PSO procedure.

$$
\begin{gathered}
\boldsymbol{x}_{i}^{(k+1)}=\boldsymbol{x}_{i}^{(k)}+\boldsymbol{v}_{i}^{(k+1)} \\
\boldsymbol{v}_{i}^{(k+1)}=\boldsymbol{v}_{i}^{(k)}+\alpha_{i}\left(\boldsymbol{x}_{i}^{\text {lbest }}-\boldsymbol{x}_{i}^{(k)}\right)+ \\
\beta_{i}\left(\boldsymbol{x}^{\text {gbest }}-\boldsymbol{x}_{i}^{(k)}\right)
\end{gathered}
$$

Where: $\quad x_{i}^{(k)}$ is the individual $i$ at iteration $k$

$v_{i}^{(k)}$ is the updated velocity of individual $i$ at iteration $k$

$\alpha_{i}, \beta_{i}$ are uniformly random numbers between $[0,1]$

$x_{i}^{\text {lbest }}$ is the individual best of individual $i$

$x^{\text {gbest }}$ is the global best of the swarm 


\section{Simulation Results}

To verify the effectiveness and performance of the particle swarm optimization, 12-node of "WA-YU" wind turbine farm project ( $8 \mathrm{MW}$ rated) was used for the test. Variable limits given in Table 1 were used as system constraints. All test cases were simulated by using the same computer which was an Intel®, Core 2 Duo, $2.4 \mathrm{GHz}, 3.0$ GB RAM.

Table 1. Variable Limits Used for load voltage derivation

\begin{tabular}{|l|c|c|}
\hline \multirow{2}{*}{\multicolumn{1}{|c|}{ Variable }} & \multicolumn{2}{c|}{ Limit } \\
\cline { 2 - 3 } & Min. & Max. \\
\hline V1 - V12 (p.u.) & 0.95 & 1.05 \\
\hline WT(Q1-Q4) (kVar) & -625 & 625 \\
\hline PF(WT1-WT4 & 0.8 & 1.0 \\
\hline WT(P1-P4) (W=MW) & 0 & 8.0 \\
\hline
\end{tabular}

The power generation from wind power is Doubly Fed Induction Generator (DFIG) to adjust the voltage at the point connection by controlling the reactive power function to optimal the real power produced is called "PF. Control". Fig. 5 shows wind turbine is rated $2 \mathrm{MW}$ per module, have 4 modules for "WA-YU" wind turbine farm project (8 MW rated). Generators in each module which receive and provide reactive power $(\mathrm{Q})$ have range between $+625 \mathrm{kVar}$ (provide) to $625 \mathrm{kVar}$ (receive) at power factor $=0.95$ (inductive/capacitive). The rated electric power at 2.0 MW can manage active power on the graph control features of the PQ wind turbine generation in Fig. 6. The method is accordance with the increase or decreases the voltage at the point of connection power systems.

The criteria defined in the analysis as follows:

- The reference bus voltage is $22.6 \mathrm{kV}$ (1.027 p.u).

- The total load on the distribution system is approximately $2.0 \mathrm{MW}$.

- The over voltage conditions are light load of industry and wind turbine generate power to grid at full capacity of 8.0 MW

- The voltage of connection pint at the industry is defined not exceed $22.80 \mathrm{kV}$ in fully generated capacity (8.0 MW) of the wind farm. Over voltage affects neighboring plant than the standard set at $23.1 \mathrm{kV}$ when the factory production line does not operate.

- The power factor converts diversion on the reactive power (Q) entered by capacitors (+Q) or inductor (-Q) of the power plant in the distribution system of PEA into the power system. (Absorb Reactive Power)

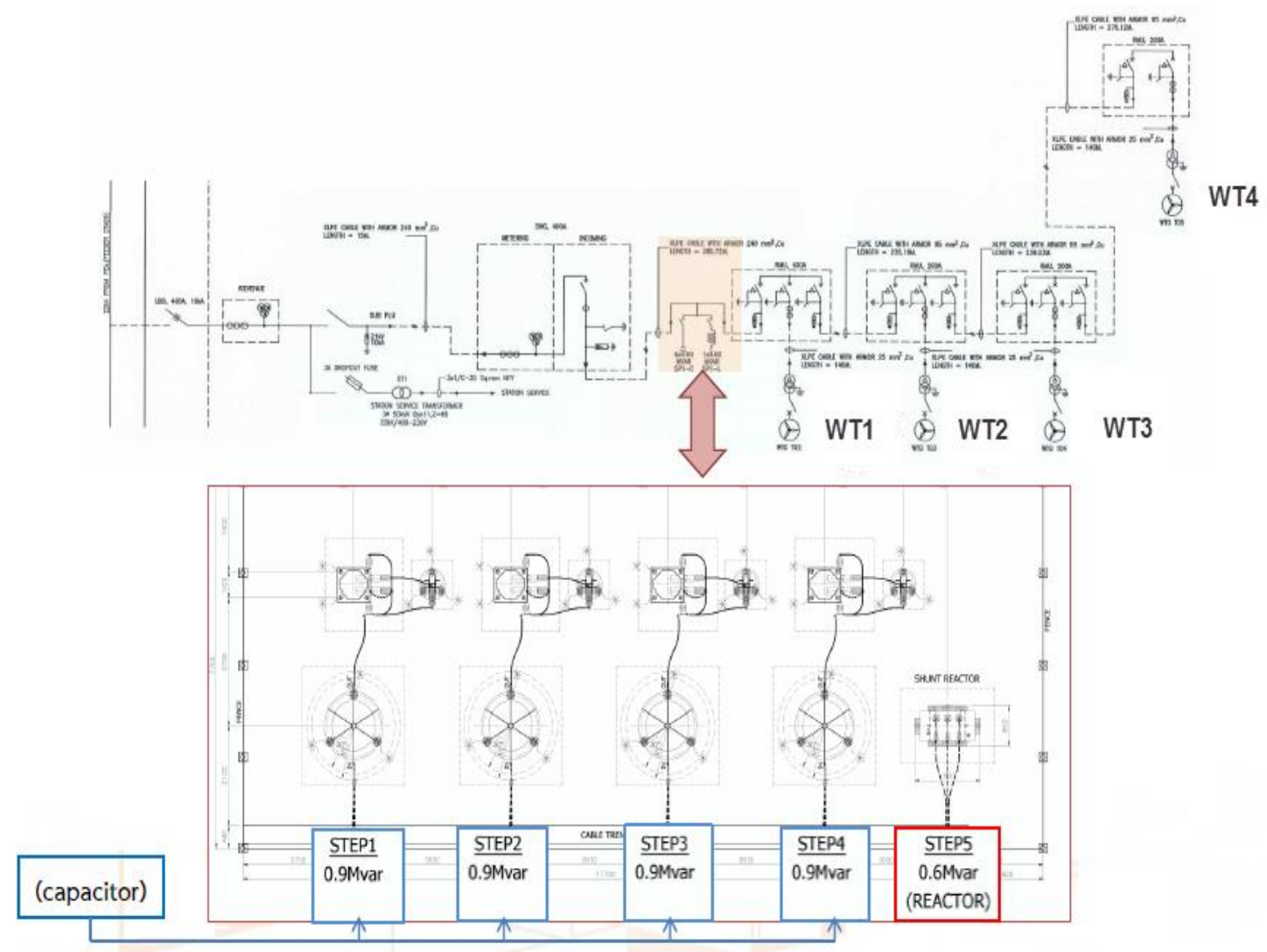

Fig. 5. Wind turbine power plant $8.0 \mathrm{MW}, 22 \mathrm{kV}$ for the test system. 


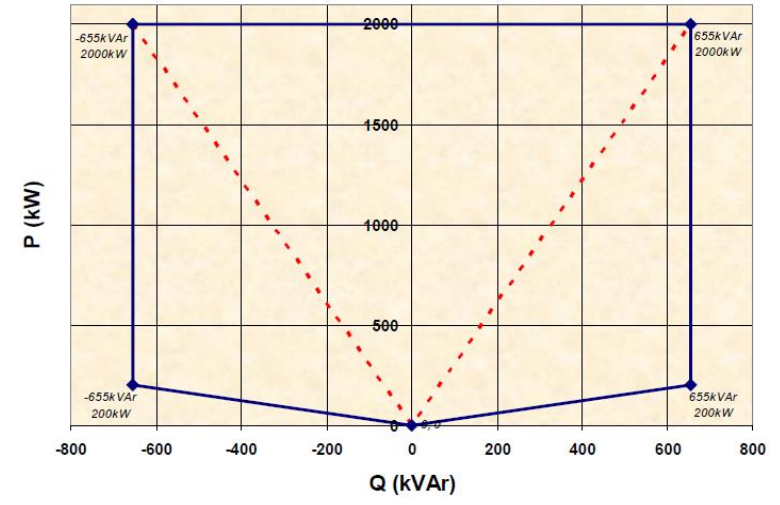

Fig. 6. P-Q characteristic of electricity power by a wind turbine.

To achieve clarity and effectiveness in solving problems at different positions, the power plant was set in PCC1 position, PCC2 were the affected factories, and power stations was in PCC3 as sourced by PEA (see Fig 7). The data measured for quality analysis from electrical disturbance analyzing device before and after corrective action is shown in Fig. 8.

Fig. 8 shows the voltage, real power and reactive power at PCC1. Over voltage occured when real power of about $5 \mathrm{MW}$ from wind farm fed to the grid level and absorbed reactive power approximately $400 \mathrm{kVAR}$. On the other hand, the PCC2 point (industrial area) had a real power demand of $2 \mathrm{MW}$ so the real power of wind turbine was excessive and high voltage effected. The overvoltage in industry area is shown in Fig 9.

Fig. 10 shows the low-side voltage of service transformer at the substation of about $418.8 \mathrm{~V}$. This is higher than the nominal voltage at $10 \%$ (considered 380 Vrms of nominal voltage) for support load demand of about 2.2 MW while the wind turbine generated real power at 5 MW.

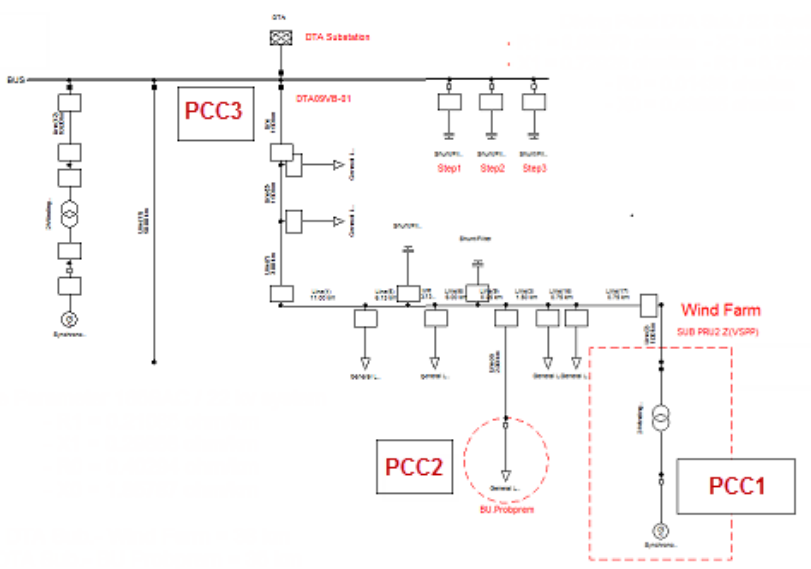

Fig. 7. The 8.0 MW rated of wind power generation system is connected to the distribution system of $22 \mathrm{kV}$ PEA.

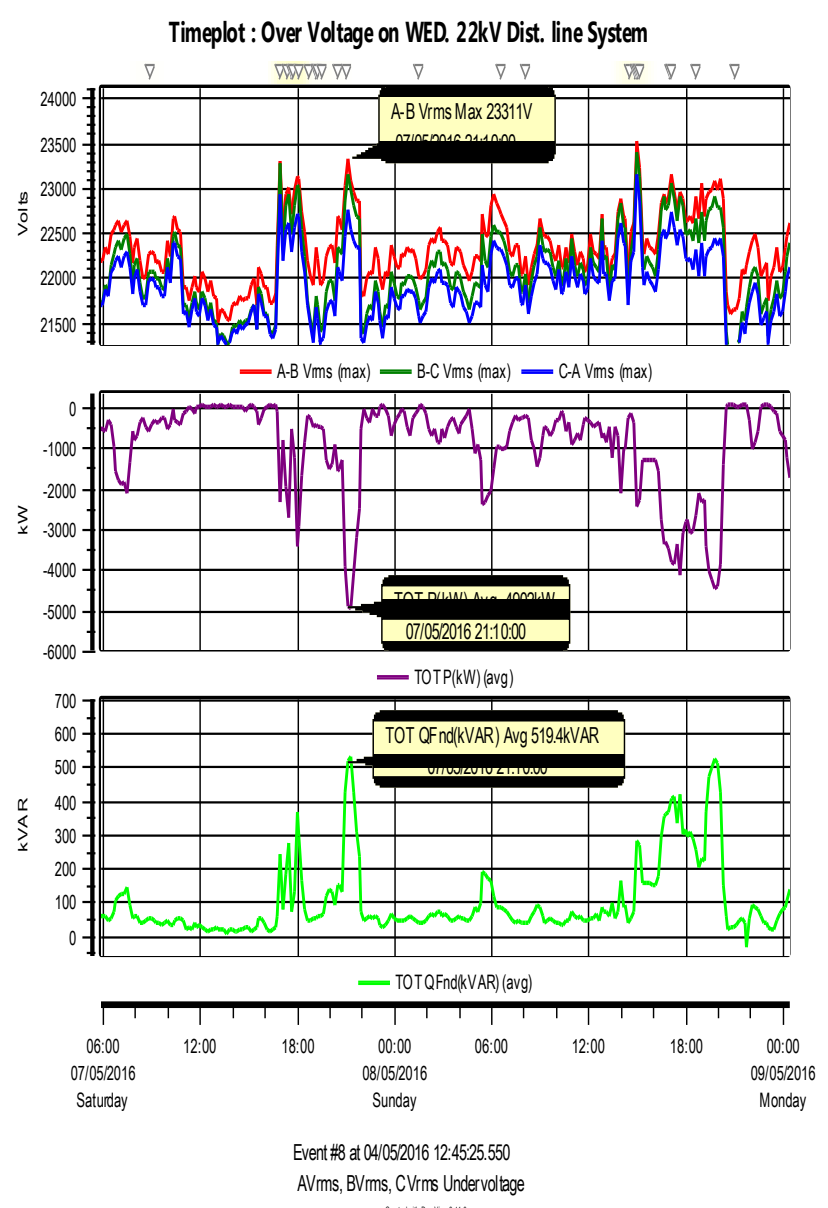

Fig. 8. State voltages are exceeded at the power plant (PCC1).
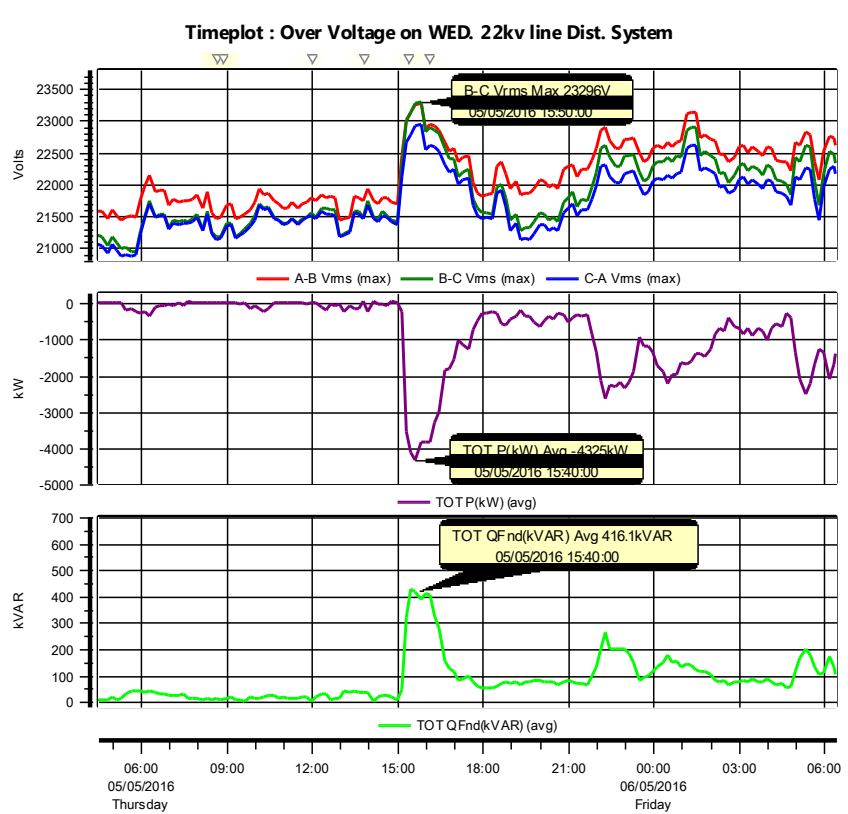

Fig. 9. Overvoltage conditions in the industrial area as plant side (PCC2). 
Timeplot: On RGE. 400V power system(Customer)

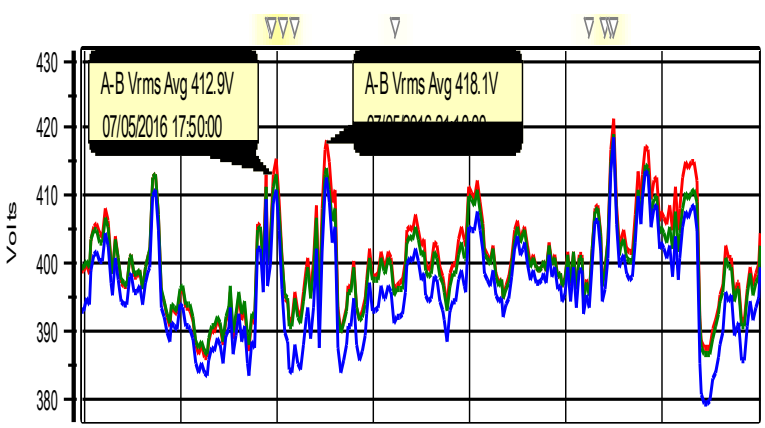

- A-B Vms (avg) $-B \cdot C V$ ms (avg) C.A Vms (avg)

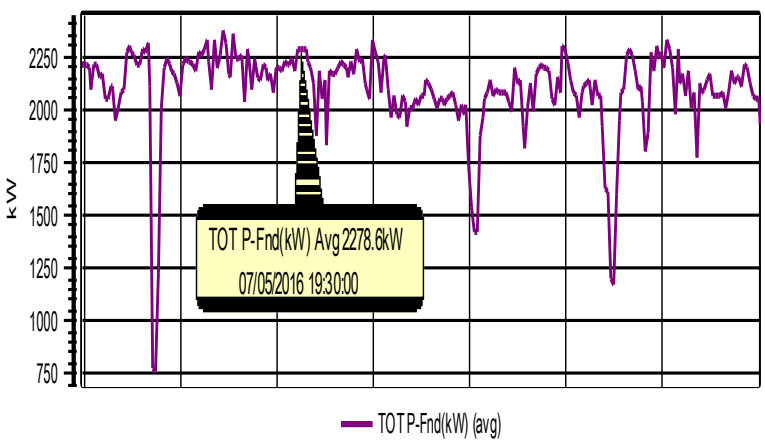

Fig. 10. The overvoltage in low-side voltage of transformer at PEA's power substation (PCC3).

Table 2 shows that when the wind turbine farm provide power to $22 \mathrm{kV}$ distribution grid of the PEA, rated of capacity ranging from $60 \%$ of installed capacity (8.0MW) may cause excessive voltage in the distribution system. The electric network of the industrial area may be affected by overvoltage because this network is in the same feeder between the wind turbine and industrial area at $22 \mathrm{kV}$ circuit. The protection device at the point of connection as the power plant's own (Over Voltage Relay releases $22 \mathrm{kV}$ Circuit Breaker on Switch Gear) and it impacts on consumers (Industrial side).

Table 2. The data record of the electric parameter at wind turbine farm.

\begin{tabular}{|c|c|c|c|c|c|c|}
\hline $\begin{array}{c}\text { Date } \\
\text { at } \\
2016\end{array}$ & Time & $\begin{array}{c}\mathrm{P} \\
(\mathrm{MW})\end{array}$ & $\begin{array}{c}\mathrm{Q} \\
(\mathrm{MVar})\end{array}$ & $\mathrm{PF}$. & $\begin{array}{c}\text { Volt- } \\
\text { age } \\
(\mathrm{kV})\end{array}$ & $\begin{array}{c}\text { Over- } \\
\text { Voltage } \\
\left(\% 22 \mathrm{kV}_{\text {nor }}\right.\end{array}$ \\
\hline $5 / 5$ & 15.40 & -6.45 & +0.65 & 0.997 & 23.30 & 5.9 \\
\hline $11 / 5$ & 15.00 & -7.35 & +0.68 & 0.999 & 23.21 & 5.5 \\
\hline $20 / 5$ & 19.30 & -7.59 & +0.91 & 0.998 & 23.60 & 7.2 \\
\hline $21 / 5$ & 12.20 & -7.81 & +0.94 & 0.999 & 23.72 & 7.8 \\
\hline $22 / 5$ & 06.00 & -7.76 & +0.92 & 0.998 & 24.05 & 9.3 \\
\hline
\end{tabular}

The proposed method in this paper can find the optimal reactive power to relate the power factor in order to minimize the load voltage derivation which is an objective function. The result showed the voltage at a wind farm was controlled on maximum capacity ( $8 \mathrm{MW}$ ) by power factor set at 0.98 lagging, where reactive power was set to feed into the grid at 1.6 Mvar (Q inductance). The load voltage derivation became 0.0002 . This result was confirmed by the methods of executing repetitive load flow ${ }^{(14)}$. The power factor of 0.98 showed to be comparable as seen in Fig. 11.

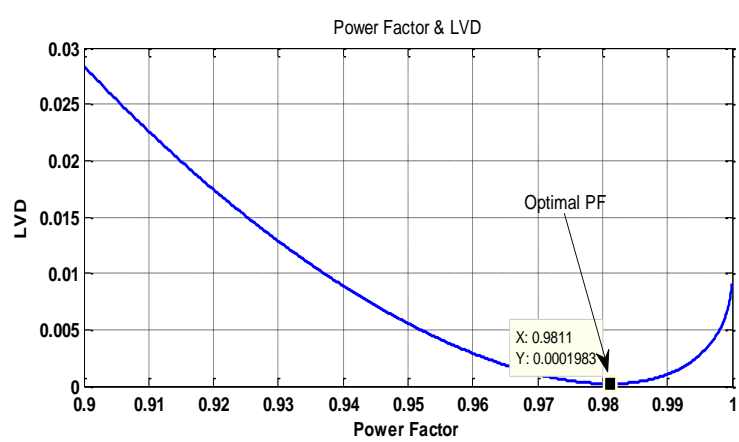

Fig. 11. Optimal power factor setting related to load voltage derivation of wind turbine power plants.

The result of setting power factor at wind turbine site using particle swarm optimization technique can regulate node voltage's wind farm at a low-side voltage as referred to PEA standard which is $22 \mathrm{kV}+5 \%$ equals to $23.1 \mathrm{kV}^{(15)}$ (as illustrated in Fig. 12.)

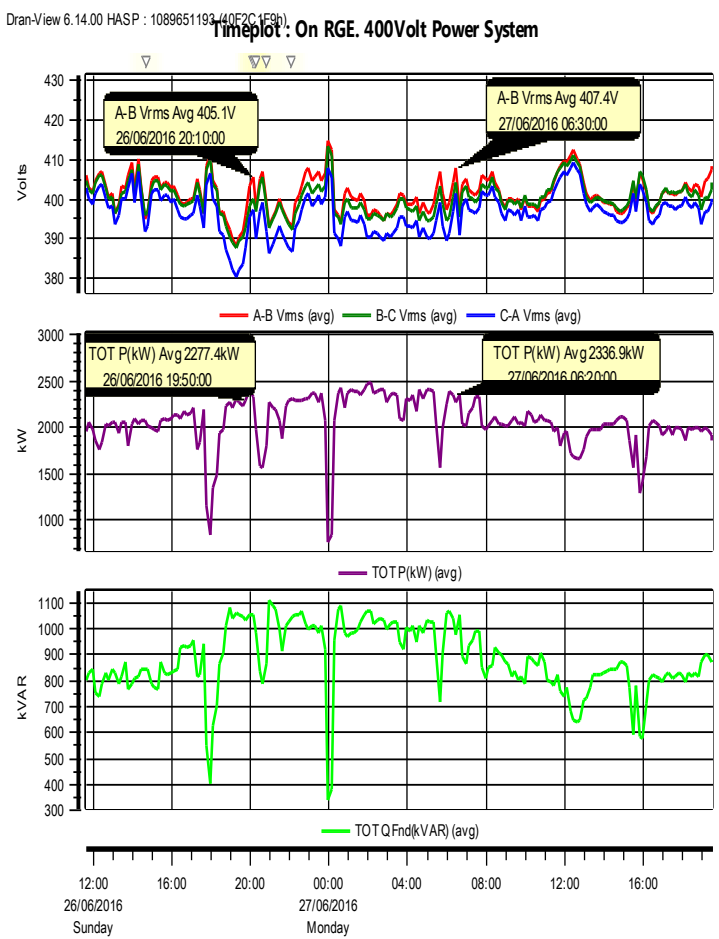

Fig 12. The result of voltage limitation is controlled related to wind turbine real/reactive power. 


\section{Conclusions}

The severity of over voltage in the $22 \mathrm{kV}$ distribution system of PEA is an impact to the industrial side caused by wind turbine power plants. The over voltage depends on real power fed to the grid and effective control voltage. This paper proposed power factor control combined with power flow analysis to consider the limitation of node voltage. The particle swarm optimization was applied to find optimal power factor and reactive power from wind turbine farm. The objective function was load voltage derivation (LVD). The success of goal was to control the voltage and keep to $22 \mathrm{kV}+5 \%$ equals to $23.1 \mathrm{kV}$ based on PEA's standard definition which is not affected by another user of the electric side. Test results were power factor setting at 0.98 (Lagging) to provide optimal active power from wind turbine fed to $22 \mathrm{kV}$ 's distribution system of PEA. The best setting of reactive power was more able to control the voltage at the connection point not so high depend on the standard of PEA. The benefit of optimal voltage control was directed to wind turbine farm, to continually provide electricity for their customers. The over voltage relay, protection device on $22 \mathrm{kV}$ switchgear cannot mistakenly operate and affect the neighbor user of electricity.

\section{References}

(1) Antonio Bracale, Pierluigi Caramia, Guido Carpinelli, Anna Rita Di Fazio and Gabriella Ferruzzi : "A Bayesian Method for Short -Term Probabilistic Forecasting of Photovoltaic Generation in Smart Grid Operation and Control", Journal of Energies, Vol. 6, pp. 733-747, 2013

(2) B .Ozerdem and H.M .Turkeli : "Wind energy potential estimation and micrositting on Izmir Institute of Technology Campus", Renewable Energy, Vol. 30, No. 10, pp.1623-1633, 2005.

(3) Zhang Yanning, Kang Longyun, Cao Binggang, Huang Chung-Neng and Wu Guohong : "Renewable energy distributed power system with wind power and biogas generator", Conference on Transmission and Distribution, pp .1 - 6, 2009.

(4) B. K. Ko, N. P. Utomo, G. S. Jang, J. H. Kim and J. T. Cho : "Optimal Scheduling for the Complementary Energy Storage System Operation Based on Smart Metering Data in the DC Distribution System”, Journal on Energies, Vol. 6, pp. 6569-6585, 2013.

(5) Z. H. Jiang, and X. W. Yu : "Modeling and control of an integrated wind power generation and energy storage system", Power and Energy Society General Meeting, pp.1-8, 2009.

(6) F.Katiraei, M.R .Iravani, and P. W. Lehn : "Micro-Grid autonomous operation during and subsequent to islanding process", IEEE Transaction on Power Delivery, Vol. 20, No. 1, pp. 248-257, 2005.

(7) F .Katiraei and M.R .Iravani : "Power management strategies for a Micro-grid with multiple distributed generation units", IEEE Transaction on Power System, Vol. 21, No. 4, pp. 1821-1831, 2006.

(8) J. Aho, A. Buckspan, J. Laks, Y. H. Jeong, F. Dunne, L. Pao, P. Fleming, M. Churchfield, and K. Johnson : “A tutorial of wind turbine control for supporting grid frequency through active power control", American Control Conference (ACC), pp .3120 -3131, 2012.

(9) power distribution, From Wikipedia, the free encyclopedia, October 2014. sources: https://en.wikipedia.org/wiki/Electric_power_distributi on.

(10) Papiya Duttal, and A. K. Sinha : "Voltage Stability Constrained Multi-Objective Optimal Power Flow using Particle Swarm Optimization", $1^{\text {st }}$ International Conference on Industrial and Information Systems, pp. 161 - 166, 2006.

(11) J. Hazra1 and A. K. Sinha : "A Study on Real and Reactive Power Optimization using Particle Swarm Optimization", International Conference on Industrial and Information Systems, pp. 323 - 328, 2007.

(12) U. Leeton, D. Uthitsunthorn, U. Kwannetr, N. Sinsuphun and T. Kulworawanichpong: "Power Loss Minimization Using Optimal Power Flow Based on Particle Swarm Optimization", The 2010 ECTI International Confernce on Electrical Engineering Electronics, Computer, Telecommunications and Information Technology,19-21 May 2010.

(13) Regulation PEA on the terms of network connectivity, the year 2008 .

(14) K. Buayai, W. Ongsakul, and N. Mithulananthan : "Multi-Objective Micro-grid Planning by NSGA-II In Primary Distribution System", European Transactions on Electrical Power, Vol. 22, No. 2, pp. 170-187, March 2012.

(15)Energy Regulatory Commission, "the purchasing power of private" sources: [http//:www.eppo.go.th / power/powerN/PICP/File/1./pdf online:11/08/2558] 